\title{
On the Third-party Evaluation and Influencing Factors of the Quality Work in Yunnan
}

\author{
Liao Jingxing, Feng Lei, Huang Juxiu \\ China National Institute of Standardization
}

\begin{abstract}
Studying and analyzing the public satisfaction index on government's quality work can help understand the situation of the quality work comprehensively and systematically and further promote the construction of a service-oriented government. This paper uses the population of permanent resident as sample and conduct the survey from various aspects, including the quality of product, project, service, environment and residents' awareness of the quality. According to the result, the scores of satisfaction evaluation have relativity with respondents' age, education and income. Meanwhile, the main factors of the satisfaction lie in drug, building security, transportation, health care and contamination, which are also public concerns.
\end{abstract}

Keywords-quality work; public satisfaction; respondents; influencing factor

\section{INTRODUCTION}

Nowadays, governments around the world are laying emphasis on their public service functions and considering "service-oriented government" as the new governance model. Since the reform and opening-up, Chinese Government has constantly reinforced its public service function and worked hard to realize the equalization of basic public services; the report on the eighteenth National Congress of the Communist Party of China put forward the goal of "building a clean and service-oriented government with scientific functions, optimized structure and high efficiency who can meet people's satisfaction". The report further clarified that the administrative system reform and function transformation should focus on gradually transforming from economic construction-oriented to public service-oriented government. Public satisfaction is the prerequisite and final objective of building service-oriented government. Thus, we should study the system of the public satisfaction index on public service, objectively evaluate the gap between the public sector's self-construction and the situation of how to meet people's demand, and analyze the reason. That has significantly theoretical and practical meaning in promoting the construction of service-oriented government that satisfies our people.

\section{SATISFACTION INDEX OF THE GOVERNMENT'S QUALITY WORK}

The survey of the satisfaction index of the government's quality work covers 5 aspects, including the quality of product, project, service, environment and residents' awareness of the quality.

Quality of the Product: it mainly includes the quality of food, medicine, agricultural products, consumer goods and special equipment. Among these products, we conduct questionnaire on agricultural goods ranging from grain, vegetable, melon, fruit, meat to aquatic products, consumer goods like durable ones and necessity, while special equipment such as elevator and the public facilities in entertainment places.

Quality of the Project: it mainly covers the quality of constructional and transportation engineering. The former aims at houses, while the latter at public transportation.

Quality of the Service: it mainly includes productive and life service quality. We conduct questionnaire about the former like public transportation, communication, web service, bank and financial service, logistics and express, as well as the life service quality including education, health care, provision for the aged, tourism and public utilities.

Quality of the Environment: it mainly covers the quality of aquatic environment and the atmosphere. The former aims at the rivers and lakes, while the latter at the air.

Awareness of the Quality: it mainly includes complaints and the information disclosure and publicity. The former focuses on the satisfaction of public's complaints, while the latter on notifying quality and safety problems and advertising the quality work.

\section{RESUlTS ON SATISFACTION EVALUATION}

In 2017, the synthetical score of the public satisfaction evaluation on Yunnan provincial government reached 65.49, raising 0.88 , compared with last year. That means people were more content with the quality work. There into, the environment quality earned the highest grade, 66.28; the awareness of the quality earned the lowest score, 64.75; the quality of service, product and project are in the middle, earning 65.67, 65.40 and 65.35.

Quality management work expenses (57z0002-2018) and National Quality Supervision Inspection and Quarantine Bureau's Science and Technology Plan Project for China Quality Work Performance Evaluation Standards System (2016QK178) 


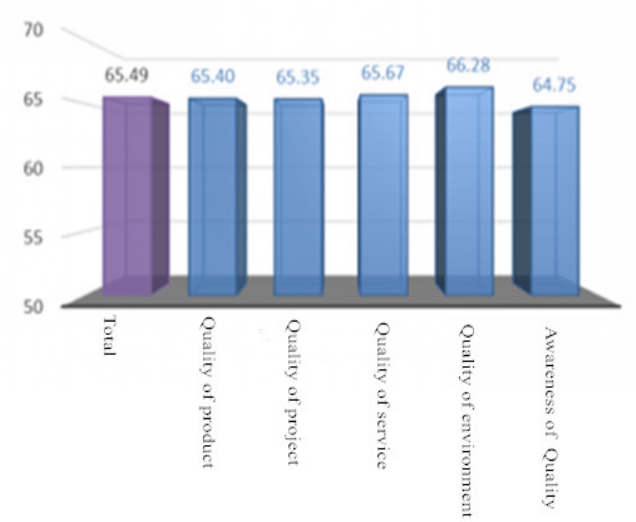

Fig. 1. Satisfaction Evaluation Scores of Yunnan Provincial Government's Quality Work in 2017

Compared with 2016, all the index rose modestly, among which the product quality increased by 2.06 , project quality by 0.41 , service quality by 0.7 , environment quality by 0.59 and quality awareness by 0.14 .

\section{A. Quality of the Product}

The comprehensive grade of the satisfaction on product quality is 65.40 , increasing 2.06, compared with last year. That means it plays an active role in supervising and inspecting the quality of the product and special rectification, so people's evaluation on product quality is on the rise. Thereinto, the respective scores of the medicine, food, agricultural product, durable goods, necessity and special equipment quality are 61.06, 64.70, 67.3, 66.46, 66.04 and 65.17. Compared with 2016, the grade of special equipment quality decreased 0.09 , but there was a quite rise in the grade of agricultural product, durable goods, necessity, food and medicine in 2017. Among them, the most obvious ascend lies in agricultural product, rising by 3.04. Guided by the government, regions actively promote the construction of the safety demonstration area of agricultural product, which drives the improvement of the quality.

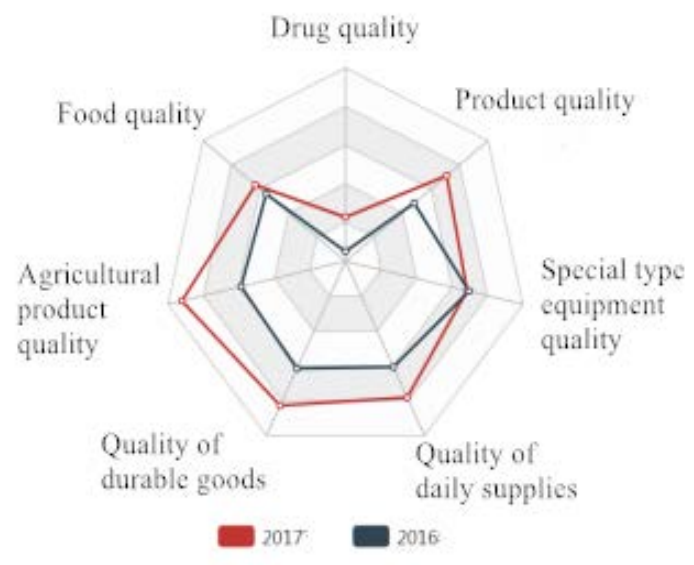

Fig. 2. Changes of the Public Satisfaction Index on the Product Quality in 2016-2017

\section{B. Quality of the Project}

The satisfaction evaluation score of the project quality reaches 65.35, increasing 0.41 over the same period. That means the provincial government pays much attention on the project quality and people's evaluation on product quality is going up. Compared with 2016, the transportation earns 65.37, rising by 1.65 , while constructional engineering earns 65.33 , housing project deceasing by 0.51 .

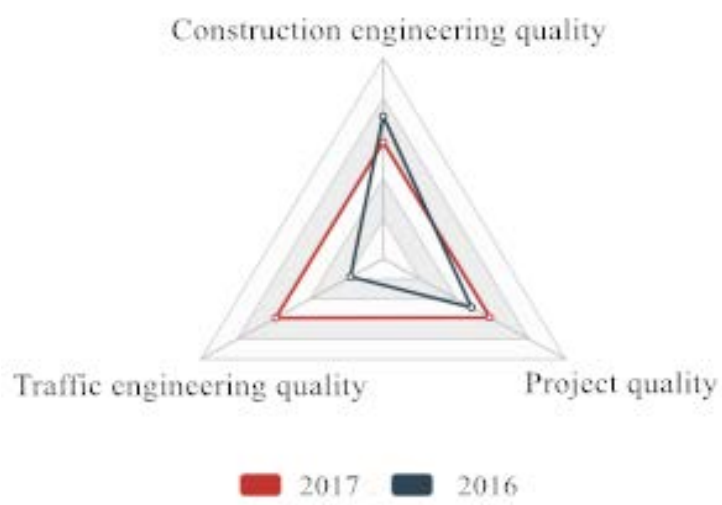

Fig. 3. Changes of the Public Satisfaction Index on Project Quality in 20162017

\section{Quality of the Service}

The public satisfaction of service quality scores 65.67, rising by 0.7 over the same period. That means our quality work of service bore fruits, so people's evaluation on product quality is on the rise. The evaluation of life service quality scores 65.98 , decreasing by 0.25 , of which the health care and provision of the aged are far from content; productive service quality scores 65.35 , decreasing 0.2 , of which the health care and provision of the aged are far from content.

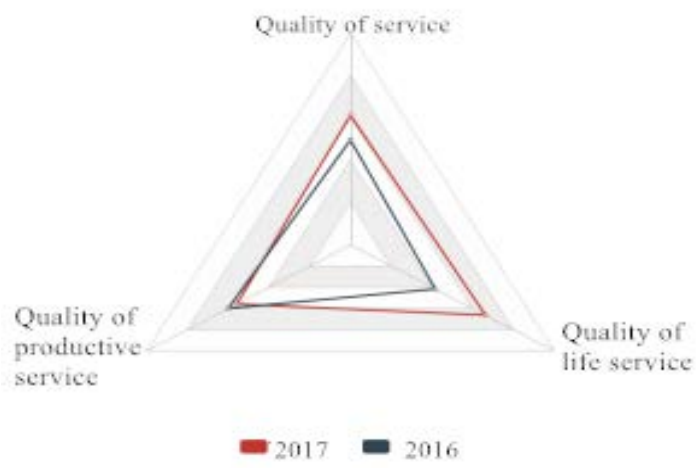

Fig. 4. Changes of the Public Satisfaction Index on Service Quality in 2016-2017

\section{Quality of the Environment}

The public satisfaction index of the environment quality reaches 66.28 , rising by 0.59 , compared with last year. The government plays an active role in comprehensive treatment on environment quality, so people's evaluation on product quality 
is on the rise. Thereinto, the air quality scores 67.56 , increasing by 0.38 , while aquatic quality of rivers and lakes scores 64.99 , increasing by 0.79 .

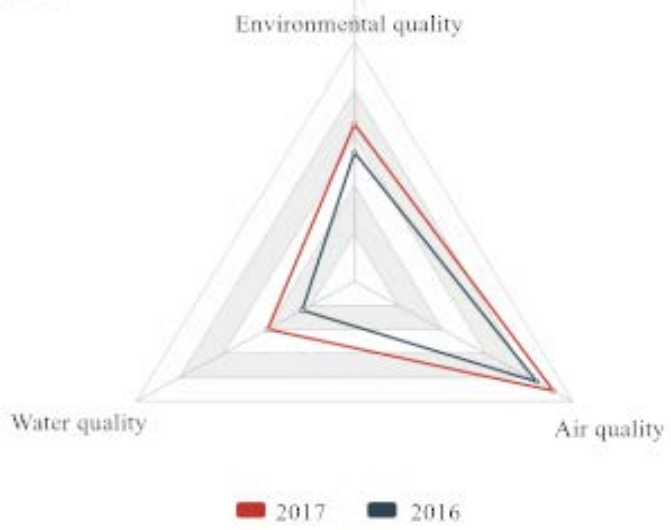

Fig. 5. Changes of the Public Satisfaction Index on Environment Quality in 2016-2017

\section{E. Residents' Awareness of the Quality}

The public satisfaction index on residents' awareness of the quality reaches 64.75, rising modestly. That means the disclosure of quality information and publicity plays an active role. The information disclosure and publicity scores 68.78, rising by 3.3; the results of complaints and reports only get 60.28 , rising by 1 . Guided by the government, locals actively strengthen the supervision of complaints and set up platforms for quality complaints, which promotes the ascend of the satisfaction evaluation on complaints.

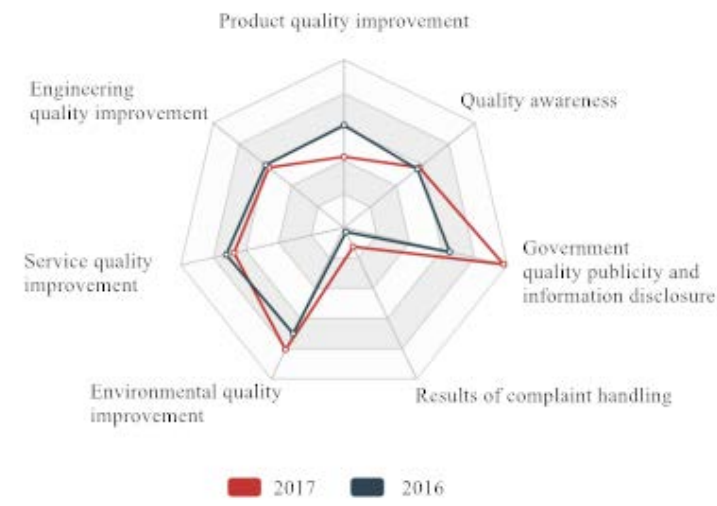

Fig. 6. Changes of the Public Satisfaction Index on Residents' Quality Awareness in 2016-2017

\section{ANALYSIS OF THE FACTORS INFLUENCING SATISFACTION}

\section{A. Analysis of the Respondents}

1) Age

According to the results, there is a close relation between the age of the respondents and the public satisfaction index of Yunnan provincial government's quality work in 2017. As they grow older, their content with government's quality work is on the rise.

Respondents aged 18 44 give the lowest grade, 65.02, to the quality work; interviewees aged 45 59 give 65.25; residents aged over 60 give 65.54 , as is shown in fig7.

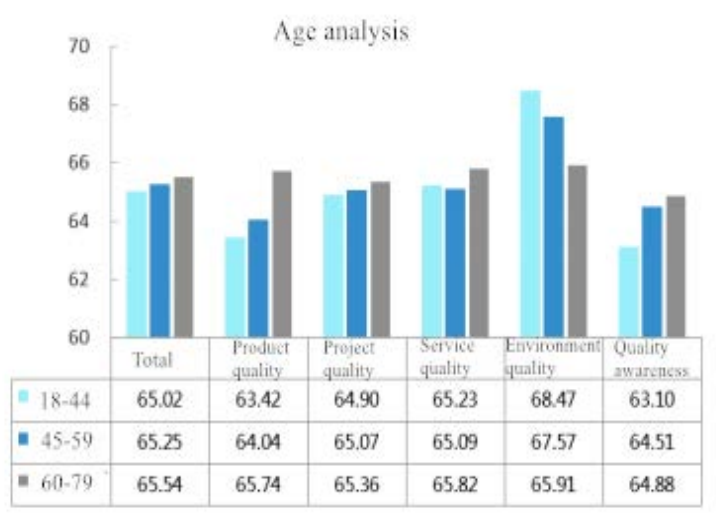

Fig. 7. Satisfaction Evaluation of Government's Quality Work from Residents in Different Age Group

\section{2) Education}

Data show that residents with college degree has high satisfaction with government's quality work, giving 66.68. With the development of education degree, the satisfaction evaluation is in decline, among which respondents with university degree give lowest grade, 62.38 . The reason is that people with higher education concern more about the quality work and have higher request for it. Therefore, they feel less content than poorly educated people.

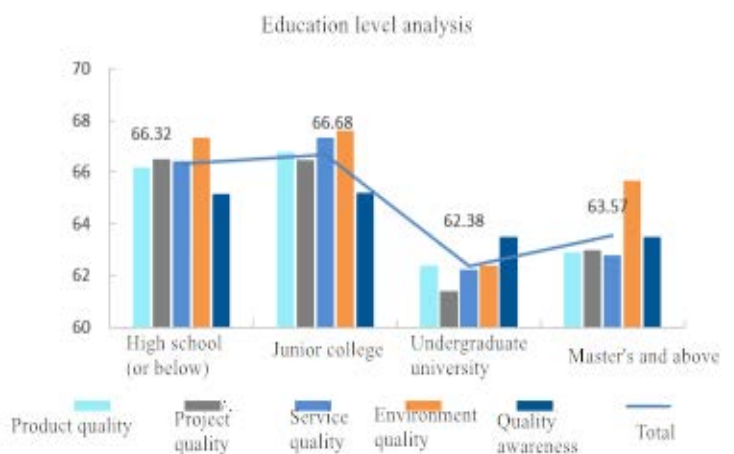

Fig. 8. Satisfaction Evaluation of Government's Quality Work from People with Different Education

\section{3) Income}

As is shown in the data, there are differences among various income groups. People with higher income feel less content than middle class. Those who earn 2001 8000 yuan per month give 66, while people earn more than 10000 yuan per month give lowest mark, 59.55. The reason is that, on the one hand, residents with high income have higher pursuit and expectation of the quality, so they are less satisfied with the reality; on the other hand, high income is closely related with 
high education and they have more request of government's quality. Therefore, the overall trend of these differences is similar.

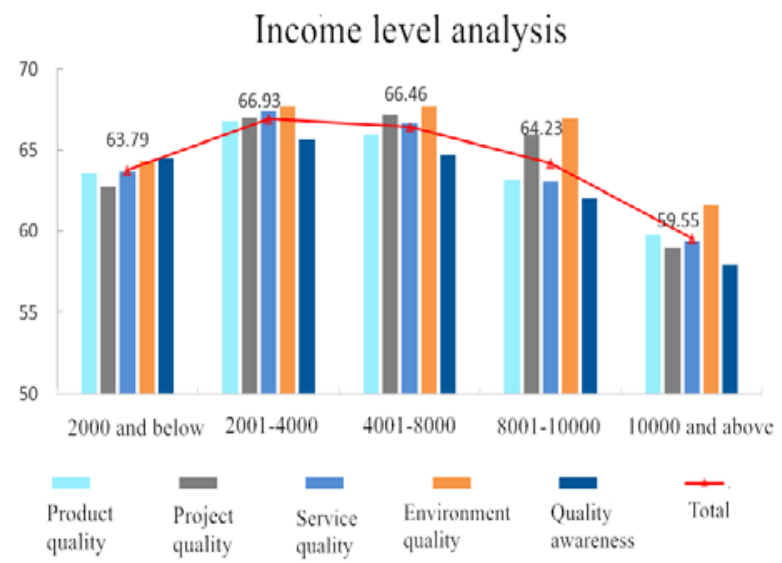

Fig. 9. Satisfaction Evaluation of Government's Quality Work from Residents with Different Income

\section{B. Analysis of the Influencing Factors}

\section{1) Quality of the Product}

In terms of the product's quality, the quality of food, medicine and special equipment has low satisfaction evaluation. There are relatively $32.37 \%, 49.09 \%$ and $34.63 \%$ of the people feel discontented. In medicine, people generally report that the drugs yield poor effects; counterfeit drugs and fake propaganda still exist. In special equipment, there still lack fitness equipment and recreational facilities. Elevator accidents occur frequently. Therefore, two important aspects affecting the quality of product lies in medicine quality and the auxiliary special equipment, which also attract public attention.

\section{2) Quality of the Project}

In the quality of the project, $67.63 \%$ of the people are satisfied with the quality of the constructional engineering. The reasons influencing public evaluation are potential security risks of the houses and housing price; $68.95 \%$ are content with the transportation. It is reported that public transit facilities are in short, traffic signs make people confused and roads are still crowded. Thus, housing and public transit facilities are main reason affecting the satisfaction evaluation of project's quality.

\section{3) Quality of the Service}

In terms of the service quality, insurance service is far from satisfaction, accounting for 53.01\%. Factors affecting people's evaluation are tough claims settlement, exaggerated advertisement and annoying phone calls. Besides, health care, short bus and e-commercial are less content, accounting for $34.19 \%$, 33.61\% and 33.57\%. The inconvenient and crowded short bus requires long waiting time; in e-commercial, the quality of the goods and trade safety still remains improving; the poor attitude of the medical staff affects the satisfaction evaluation.

\section{4) Quality of the Environment}

$60.64 \%$ of the people are satisfied with the aquatic environment. Water containment still remains the main reason affecting public evaluation.

\section{5) Residents' awareness of the quality}

$55.42 \%$ are discontent with the complaint handling. It is reported that people have to wait quite long time to complain without satisfied answers.

\section{CONCLUSION AND SUGGESTION}

This article uses permanent residents as sample, gathers data by telephone, online and on spot and conduct survey and analysis of the quality of product, project, service, environment and residents' awareness of the quality. Conclusions are as follows.

(1)There is modest relation between the satisfaction and respondents' age, education and income. These three factors are inversely proportional to the participation and perception of the quality work.

(2)The main reasons influencing product's quality are counterfeit drugs and fake propaganda; the problems affecting project's quality are housing security and price and insufficient public transit facilities; service quality still remains problems like insurance claims, annoying phone calls, crowded transportation and attitude of medical staff; aquatic pollution and complaint handling are main factors affecting environment and residents' awareness of quality.

For above results, we suggest that, according to different influencing factors, government should conduct customized quality work, realizing targeted docking between the demand and supply. Then government should specifically improve public satisfaction for quality work, further increasing the overall quality of the product, project, service and environment.

\section{REFERENCES}

[1] Wang Dianli, Song Xuezeng. An Empirical Research on Satisfaction of Public Services[J].Chinese Public Administration, 2009(6):72-77.

[2] Luo Xiaoguang, Zhang Hongyan. Dimensional Analysis of SERVQUA L on Government's Service Quality[J].Administrative Tribune, 2008 (3): 35-37.

[3] Cui Guifang.Discussion on the Development of Managing the Service Quality of the Government[J].Hubei Social Sciences,2005(8): 37-38.

[4] Li Wenbin, Lai Linhui. Relation Between Government Performances Satisfaction and Residents' Happiness-Based on Empirical Research of Guangdong Province[J].Chinese Public Administration, 2013(8):53-57.

[5] Zhang E'e, Zhang Jing. A Customer Satisfaction of Agricultural Products Quality and Safety of Yongning County-Based on the Survey Data from the Residents of Five Towns in Yongning County[J].Journal of Agricultural Sciences, 2017(3):92-96. 